Relations industrielles

Industrial Relations

\title{
Social Deviance, Social Policy, Action and Research, Leslie T. Wilkins, Prentice-Hall Inc., Englewood Cliffs, New Jersey, 1965. 305 pages.
}

\section{Jeanne Michaud}

Volume 21, numéro 3, 1966

URI : https://id.erudit.org/iderudit/027715ar

DOI : https://doi.org/10.7202/027715ar

Aller au sommaire du numéro

Éditeur(s)

Département des relations industrielles de l'Université Laval

ISSN

0034-379X (imprimé)

1703-8138 (numérique)

Découvrir la revue

Citer ce compte rendu

Michaud, J. (1966). Compte rendu de [Social Deviance, Social Policy, Action and Research, Leslie T. Wilkins, Prentice-Hall Inc., Englewood Cliffs, New Jersey, 1965. 305 pages.] Relations industrielles / Industrial Relations, 21(3), 465-465. https://doi.org/10.7202/027715ar

Tous droits réservés (C Département des relations industrielles de l'Université Laval, 1966
Ce document est protégé par la loi sur le droit d'auteur. L'utilisation des services d’Érudit (y compris la reproduction) est assujettie à sa politique d'utilisation que vous pouvez consulter en ligne.

https://apropos.erudit.org/fr/usagers/politique-dutilisation/ 
Ces études statistiques peuvent nous sensibiliser aux nombreux problèmes que rencontrent les jeunes sur le marché du travail. Dans une deuxième partie, les auteurs poussent plus loin leur analyse et essaient de voir * comment les jeunes eux-mêmes s'éprouvent au milieu des difficultés qu'ils affrontent». On se penche sur les attitudes au travail des jeunes ouvriers et sur la connaissance du métier futur que peuvent avoir les * scolaires ». Puis à partir de différents " éléments professionnels » se dégagent quatre "situations-types» de travail sur lesquelles l'âge, le sexe et le métier auront une incidence. Enfin, dans une troisième partie, on cherche à savoir comment les jeunes choisissent leur école ou leur travail, qu'estce qui les motive et quels éléments influencent leurs choix.

Dans l'ensemble l'ouvrage semble nous donner une vue objective des différents problèmes et situations auxquelles les jeunes du milieu populaire ont à faire face dans le monde du travail; il nous permet « d'approcher la réaction subjective des jeunes du milieu populaire à la situation qui leur est faite ou devant l'avenir qui leur est tracé-»

\section{Gaston OUELLET}

Social Deviance, Social Policy, Action and Research, Leslie T. Wilkins, Prentice-Hall Inc., Englewood Cliffs, New Jersey, 1965. 305 pages.

Ce volume apporte au lecteur une étude des liens qui existent entre la recherche, la politique et le travail social. Après avoir expliqué la nature d'une étude scientifique, les distinctions entre l'action et la recherche, I'auteur précise le rôle de la théorie.

II constate la différence de langages qui se trouve entre théorie et pratique, dans les sciences de I'homme; il fait remarquer que le monde, l'objet étudié, est le même, mais que la théorie ne peut tenir compte des composantes affectives et émotionnelles des hommes; elle doit aussi mettre de côté les répétitions, les redondances que rencontre le praticien. C'est pourquoi théorie et pratique, recherche et action adoptent des langages différents, en parlant d'un même monde.

L'auteur applique ces considérations ou concept de « déviation sociale». II discute des sources de difficultés de communications, entre sciences pures et appliquées et il donne des suggestions de simplification. Si son application porte seulement sur les comportements anormaux ou pathologiques des hom- mes, c'est qu'il considère tous les problèmes sociaux, comme fondamentalement semblables; ainsi en expliquant les relations théoriepratique, par rapport au crime, l'auteur estime apporter les éléments de solution aux autres difficultés de ce genre.

Leslie T. Wilkins est "Senior Adviser * à l'Institut des Nations Unies d'Asie et d'Extrême-Orient, Tokyo, Japon; il est de nationalité anglaise; il a reçu le "Francis Wood Memorial Prize » de la Société Statistique Royale.

\section{Jeanne MICHAUD}

\section{Crime and Its Treatment in Canada, W.T.}

McGrath, Ed. The Macmillan Company of Canada Ltd., Toronto, 1965. 509 pages.

L'année 1965 a été marquée par une prise de conscience progressive des problèmes suscités par la criminalité et le système pénal canadien. Aussi le gouvernement fédéral du Canada a créé, en avril 1965, une Commission d'enquête sur la pénalité. Un intérêt à ces questions a été également à I'origine de la publication du volume que nous présentons ici. Celui-ci réunit seize exposés d'auteurs différents, sur les principaux aspects du crime et de la réhabilitation du criminel, au Canada, soit: les rapports crime et société; le taux de la délinquance ; le rôle de la police; I'organisation et lé fonctionnement des Cours de Justice; les formes d'institutions pénitentiaires; la libération conditionnelle: sa préparation, son organisation, ses difficultés: les réformes pénales et correctionnelles; le traitement du criminel

De plus, ces études, pour la plupart, sont accompagnées d'une bibliographie. Les auteurs se recrutent parmi des psychiatres, des avocats, des travailleurs sociaux, etc.; les uns occupent des postes de direction dans les institutions pénitentiaires et policières; d'autres se retrouvent dans l'enseignement ou la recherche; d'autres jouent un rôle de thérapeute, auprès des criminels... Ainsi la variété de la formation et des occupations des auteurs et la diversité des aspects traités procurent au lecteur une vue générale sur l'état actuel du crime et du système pénal canadien. Ce livre permet enfin de faire un pas plus avant, vers une coordination, une synthèse des opinions et points de vue des diverses spécialités intéressées, à la lumière des développements récents des sciences de I'homme.

Jeanne MICHAUD 